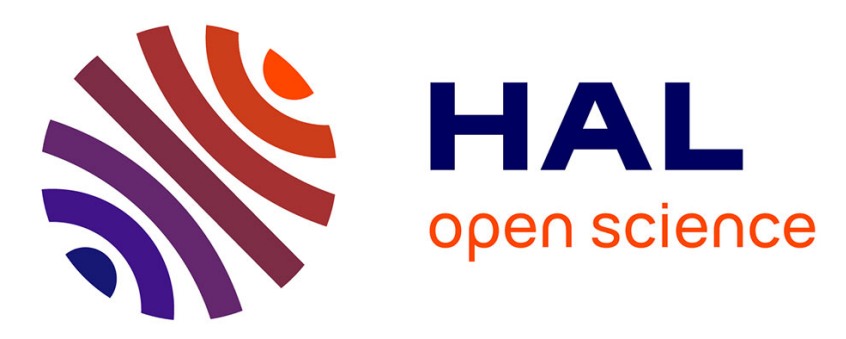

\title{
Design and Synthesis of Aniline-Appended P3HT for Single Step Covalent Functionalisation of Carbon Nanotubes
}

Felipe Wasem Klein, Jean-Philippe Lamps, Mohamed Raoui, Matthieu

Paillet, Jean-Louis Sauvajol, Philippe Mésini, Pierre Petit

\section{To cite this version:}

Felipe Wasem Klein, Jean-Philippe Lamps, Mohamed Raoui, Matthieu Paillet, Jean-Louis Sauvajol, et al.. Design and Synthesis of Aniline-Appended P3HT for Single Step Covalent Functionalisation of Carbon Nanotubes. Polymer Chemistry, 2020, 11 (39), pp.6319-6327. 10.1039/d0py01147a . hal02965425

\section{HAL Id: hal-02965425 \\ https://hal.science/hal-02965425}

Submitted on 15 Oct 2020

HAL is a multi-disciplinary open access archive for the deposit and dissemination of scientific research documents, whether they are published or not. The documents may come from teaching and research institutions in France or abroad, or from public or private research centers.
L'archive ouverte pluridisciplinaire HAL, est destinée au dépôt et à la diffusion de documents scientifiques de niveau recherche, publiés ou non, émanant des établissements d'enseignement et de recherche français ou étrangers, des laboratoires publics ou privés. 


\section{Design and Synthesis of Aniline-Appended P3HT}

\section{for Single Step Covalent Functionalisation of}

\section{Carbon Nanotubes}

Felipe Wasem Klein ${ }^{a}$, Jean-Philippe Lamps ${ }^{a}$, Mohamed Raoui ${ }^{a}$, Matthieu Paillet ${ }^{b}$, JeanLouis Sauvajol ${ }^{b}$ Philippe J. Mésini $^{a, c}$ and Pierre Petit ${ }^{a} *$

\footnotetext{
a Université de Strasbourg, CNRS, Institut Charles Sadron UPR22, F67000 Strasbourg, France.

${ }^{\mathrm{b}}$ Laboratoire Charles Coulomb(L2C), Université de Montpellier, CNRS, Montpellier, France.

${ }^{\mathrm{c}}$ International Center for Frontier Research in Chemistry, Strasbourg, France.
}

\section{CORRESPONDING AUTHOR}

*E-mail: pierre.petit@ics-cnrs.unistra.fr

Institut Charles Sadron, 23 rue du Loess, 67034 Strasbourg France 
The synthesis of a copolymer derived from poly(3-hexylthiophene), one of the monomers bearing an aniline group, is described. Like the homopolymer, this copolymer is able to functionalize carbon nanotubes by $\pi$-stacking of the thiophene units onto the hexagonal network of the nanotubes. It can as well be covalently attached onto carbon nanotubes walls without the need of an intermediate chemical step. While the dispersion of the non-covalent nanohybrids in THF is stable for few hours only, the one of the covalent nanohybrids is stable for weeks, showing the efficiency of the functionalization. The comparison between spectroscopic characterizations of both covalent and non-covalent systems shows that the copolymer organizes differently at the interface with the nanotubes in each case, in agreement with the effectiveness of the reaction of addition.

KEYWORDS: Poly(3-hexylthiophene) derivative, Single Wall Carbon Nanotubes, covalent functionalization, Optical Absorption, Photoluminescence, Raman Spectroscopy 


\section{INTRODUCTION}

Much work dealing with covalent and non-covalent functionalization of carbon nanotubes by conjugated polymers, among them poly(3-hexylthiophene) (P3HT), has been performed in order to elaborate new nanohybrids, in the solid state or in solution. In the case of covalent nanohybrids, single-wall carbon nanotubes (SWNTs) are firstly oxidized ${ }^{1-4}$ or reacted with a small molecule such as 4-substituted anilines. ${ }^{5,6}$ A polymer can be grafted onto or from the resulting side groups. This two steps route makes difficult to predict an estimate of the functionalization rate and renders identical experiments difficult to compare.

In the present work, we report an alternative route by designing and synthesizing a statistical copolymer derived from P3HT able to be grafted directly onto SWNTs by the side chains. We chose a low ratio of reactive to non-reactive comonomers in order to prevent too strong modifications of the structure of the SWNTs. ${ }^{7}$ This route may lead to nanohybrids with peculiar optical properties such as the brightening of SWNTs photoluminescence. ${ }^{8,9}$

Using this copolymer, we first functionalized SWNTs non-covalently in order to get the most dispersed suspension of functionalized isolated nanotubes (hereafter called non-covalent nanohybrid); then we used such suspensions to functionalize them covalently in situ (hereafter called covalent nanohybrid). The stability of the resulting suspensions and the comparison between the physico-chemical properties of both nanohybrids show that the nanotubecopolymer interfaces in both systems are drastically different, as are the interchain interactions, in agreement with the effectiveness of the covalent functionalization.

\section{RESULTS AND DISCUSSION}

The copolymers we targeted have a P3HT backbone where some of the side chains are functionalized with aniline groups at their end (Scheme 1). The aniline group can react with the SWNTs by Tour's reaction: $:^{10}$ the aniline is converted in situ to its diazonium, which alkylates the SWNTs. 


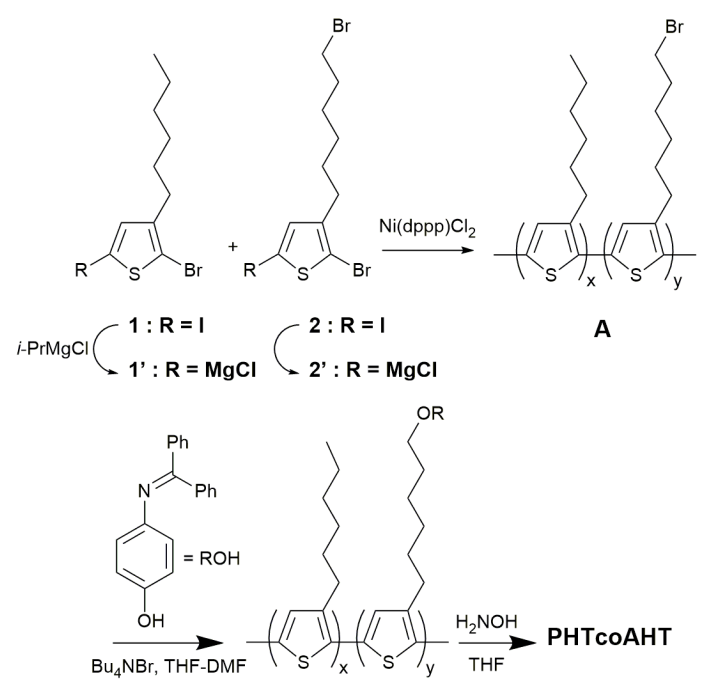

B

Scheme 1. Synthesis of the reactive copolymer.

The targeted polymers were synthesized by GRIM polymerization, developed by the groups of $\mathrm{McCullough}^{11}$ and Yokozawa $^{12}$, and proved to reach quasi-control and good regioregularity. Alkylthiophene monomers bearing a bromine at the end of the side chains have been successfully polymerized by this method, showing that no side reaction occurs at the bromide of the side chains. ${ }^{13}$ GRIM copolymerization of 3-alkylthiophenes with close structures have been shown to yield random copolymers. ${ }^{14}$ We have copolymerized the 5-iodo 2-bromo monomers $\mathbf{1}$ and $\mathbf{2}$. Their structures differ only by the bromine on the end of side chain. We fixed the molar proportion of $\mathbf{2}$ at $15 \%$. This ratio has been chosen to avoid a too strong alteration of the nanotubes structure after their functionalization. It should lead at maximum to a few covalent links per thousand SWNT carbon atoms. Before the polymerization itself, $\mathbf{1}$ and $\mathbf{2}$ are metallated by the exchange of iodine with $i \mathrm{PrMgCl}$ to yield the monomers 10̂and 20̂ We have measured the conversion rate of this step by the method of Catala: ${ }^{15}$ after metallation, an aliquot of the solution was quenched with $\mathrm{CD}_{3} \mathrm{OD}$ and observed 
by NMR. The hydrolysis of 10̂and 20̂forms the corresponding compounds deuterated in 5, identified by a singlet at $6.78 \mathrm{ppm}$. Beside this major compound, the NMR spectra also show unreacted 1 or 2 (singlet at $6.95 \mathrm{ppm}$ ), and 3-alkyl-2-bromothiophene (doublet at $7.17 \mathrm{ppm}$ ) coming from the hydrolysis of $\mathbf{1 0}$ or $\mathbf{2} \mathbf{0}$ by protonated impurities in the reaction medium (Figure S1, Supporting Information). This analysis provides the rate of active monomer (ca 90 $\%$ ), and the required amount of catalyst for the targeted degree of polymerization. It also proves that the bromide on the side chain is not affected by the organomagnesium and that metallation takes place only at position 5 .

The polymerization was achieved by addition of the catalyst and followed by UV-vis. It yielded the brominated copolymer (copolymer $\mathbf{A}$ in Scheme 1) with an average mass $M_{\mathrm{n}}$ of $36000 \mathrm{~g} \mathrm{~mol}^{-1}\left(5200 \mathrm{~g} \mathrm{~mol}^{-1}\right)$ and a dispersity of 1.41 (1.12). The fraction of side bromide was derived from the ratio of the integrals of the peaks of the vicinal protons of $\mathrm{Br}$ (triplet at 3.43 ppm) to those of the $\alpha$-methylene (multiplet at $2.81 \mathrm{ppm}$ ) and was estimated to $15 \pm 2 \%$ for $M_{\mathrm{n}}$ of $36000 \mathrm{~g} \mathrm{~mol}^{-1}\left(14 \pm 2 \%\right.$ for $M_{\mathrm{n}}$ of $\left.5200 \mathrm{~g} \mathrm{~mol}^{-1}\right)$, in register with the feed ratio Table 1).

Table 1. Characteristics of the copolymers A

\begin{tabular}{llll}
\hline Copolymer & $\begin{array}{l}M_{\mathrm{n}} \\
\left.\left[\mathrm{g} \mathrm{mol}^{-1}\right]^{\mathrm{a}}\right)\end{array}$ & $\mathrm{P}$ & $\begin{array}{l}\text { Rate of Br-hexyl } \\
{[\%]^{\mathrm{b})}}\end{array}$ \\
\hline $\mathbf{A ~ 5 0 0 0}$ & 5200 & 1.1 & $14 \pm 2$ \\
$\mathbf{A} \mathbf{3 6 0 0 0}$ & 36000 & 1.41 & $15 \pm 2$ \\
\hline${ }^{\text {a) }}$ determined by SEC-MALS (Figure S2, Supporting Information); ${ }^{\text {b) }}$ determined by NMR
\end{tabular}

The regioregularity of the copolymer was estimated by comparing the intensity of the signals of the proton 4 of the thiophene, according to the assignment of the literature. Especially, the signal for the proton thiophene at $6.97 \mathrm{ppm}$, assigned to HT-HT triads ${ }^{16,17}$ 
represents more than $99 \%$ of the signal. Copolymerization was conducted with different feed rates of $\mathbf{2}(5 \%, 16 \%$ and $25 \%)$; at a conversion rate $<10 \%$, the molar fraction of units $\mathbf{2}$ in the polymer follows the feed ratio (Figure S3, Supporting Information), showing that the comonomers have close reactivities and yield random copolymers.

In the precursor brominated copolymer, the bromide was substituted by p-hydroxyaniline protected as its diphenylmethylenimine (copolymer $\mathbf{B}$ in Scheme 1). This functionalization yield is higher than $98 \%$ under phase transfer catalyst conditions. The rate of substitution of the bromine was estimated by NMR (Figure S4, Supporting Information) by the comparison of the integrals of the $\mathrm{CH}_{2} \mathrm{O}$ protons at 3.87 and the residual integral at $3.43 \mathrm{ppm}$ (shift of the $\mathrm{CH}_{2} \mathrm{Br}$ protons). The imine could not be hydrolyzed by acid catalysis in $\mathrm{H}_{2} \mathrm{O} / \mathrm{THF}$ mixture because it led to phase separations during the reaction. Therefore, the aniline was deprotected by aminolysis with hydroxylamine yielding to the reacting copolymer PHTcoAHT (Scheme 1). ${ }^{18,19}$

First, non-covalent functionalization of SWNTs was performed in order to define a suitable mass ratio SWNT/PHTcoAHT allowing one to get a stable suspension of the nanohybrid. For that purpose, we have prepared a mother suspension of SWNTs in THF $\left(175 \mathrm{mg} \mathrm{L}^{-1}\right)$ and added successive amounts of $200 \mu \mathrm{L}$ (corresponding to 0.32 SWNTs/Copolymer weight ratio) of it to a $4 \mathrm{~mL}$ solution of PHTcoAHT 36000 in THF (28.8 $\left.\mathrm{mg} \mathrm{L}^{-1}\right)$. The process was repeated until the suspension became unstable and flocculated. The same procedure was used to prepare suspensions of SWNT/PHTcoAHT 5000 in THF (concentration of the mother solution of SWNTs in THF: $150 \mathrm{mg} \mathrm{L}^{-1}$, successive additions of $40 \mu \mathrm{L}$ of it to a solution of PHTcoAHT 5000 having a concentration of $31.9 \mathrm{mg} \mathrm{L}^{-1}$ ).

All these suspensions are stable for few hours depending on the concentration of nanotubes, after which they eventually slowly flocculate. However, above a critical SWNTs/copolymer mass ratio, flocculation occurs immediately. This ratio is 1.26 for $M_{\mathrm{n}} 36000 \mathrm{~g} \mathrm{~mol}^{-1}$ and 0.47 
for $5000 \mathrm{~g} \mathrm{~mol}^{-1}$ indicating that the longer the polymer chain the larger amount of SWNTs suspended. Such an effect of polymer molecular weight has already been reported for polyfluorene $^{20}$ and polycarbazole. ${ }^{21}$ It can be emphasized that the stability of SWNT/PHTcoAHT 36000 suspensions (below the critical mass ratio) for few hours is a first evidence that copolymer chains are in close interaction with nanotubes. Indeed, suspensions of SWNTs in THF (without copolymer) at the same concentration are strongly instable.
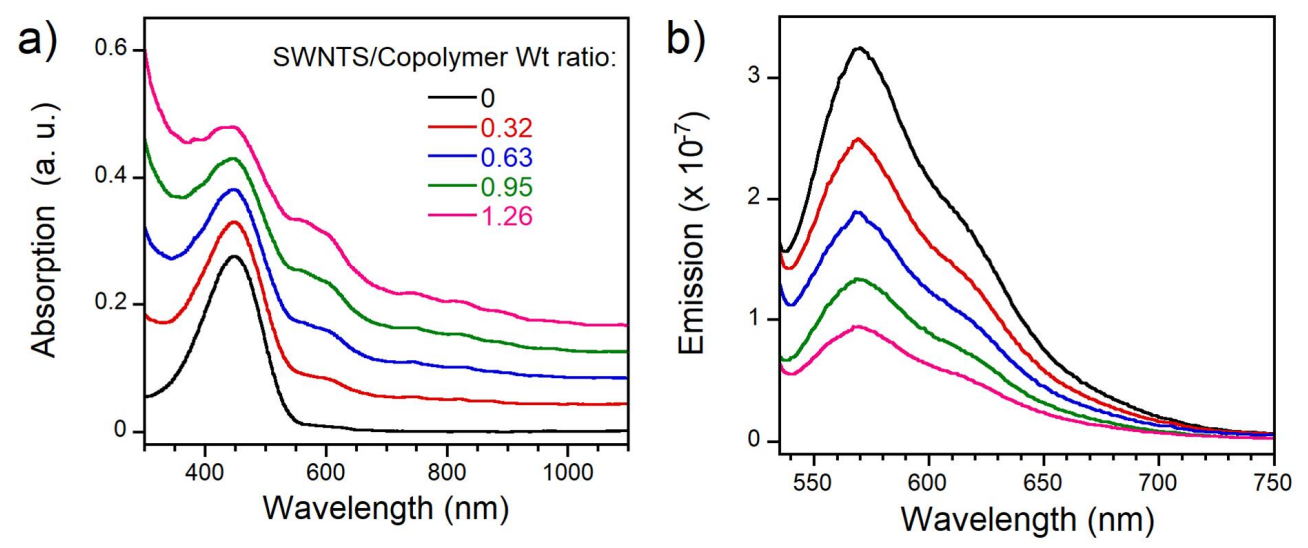

Figure 1. Evolution of the (a) optical absorption and (b) photoluminescence spectra of SWNTs/PHTcoAHT 36000 suspensions as a function of wt. ratio. A weight ratio of 0.32 corresponds to a single addition of SWNTs.

Non-covalent functionalization of SWNTs was monitored by UV-Vis absorption (Figure 1a) and photoluminescence spectroscopy (Figure 1b). Note that the last spectrum displayed on Figure 1 (and Figure S5, Supporting Information) corresponds to the highest weight ratio for which the suspension is stable.

When the concentration of SWNTs increases, UV-Vis spectra show a decrease of the absorption of the free copolymer at $450 \mathrm{~nm}(2.75 \mathrm{eV})$ accompanied by a relative increase of a broad unresolved band between $530 \mathrm{~nm}(2.34 \mathrm{eV})$ and $630 \mathrm{~nm}(1.97 \mathrm{eV})$. Such behavior was previously observed on solutions of regioregular P3HT in various solvents and was assigned 
as the signature of the formation of aggregates (crystallites) due to interchain interactions between thiophene units as the chains extend and planarize. ${ }^{22,23}$ On the basis of these results, we can conclude on the formation of such aggregates in the SWNT/PHTcoAHT suspensions in THF. The formation of these aggregates is clearly enhanced by the amount of SWNTs present in the suspensions. Consequently, we can reasonably assume that this enhancement is caused by the interaction ( $\pi$-stacking) of the polymeric chains with the nanotubes. In other words, SWNTs play the role of growth nuclei for the aggregates of PHTcoAHT chains. It can be also emphasized that the length of the polymeric chain plays a role in the formation of aggregates; longer the chain is larger the amount of SWNTs suspended (as shown by comparing Figure 1a and Figure S5a). This can be understood as due to the increase of the interaction between polymeric chain and SWNTs with the chain length. Finally, the presence of a weak aggregate band in the solution of PHTcoAHT in THF without SWNTs is due to the relatively high concentration of the copolymer in the starting solution. This relatively high concentration was choosen to ensure the dispersion of a sufficient ammount of SWNTs to be easely detectable. However, the same experiments performed on low concentrated copolymer solutions show the same behaviour (Figure S6, Supporting Information) and a comparable critical mass ratio is obtained. These results indicate that the concentration of the PHTcoAHT solution and the possible presence of initial agregates have no incidence on the reported overall behaviour.

The photoluminescence (PL) band of PHTcoAHT in solution in THF without SWNTs shows a $0-0$ emission peak (the most intense) located around $570 \mathrm{~nm}(2.17 \mathrm{eV})$ and $0-1$ emission peak around $620 \mathrm{~nm}(2.0 \mathrm{eV})$ (Figure 1b and Figure S5b, in Supporting Information). The gap between the two emission peaks, close of $0.18 \mathrm{eV}$, indicates that the $\mathrm{C}=\mathrm{C}$ symmetric stretch dominates the coupling to the electronic transition. ${ }^{23}$ 
The increase of SWNTs concentration leads to a global decrease of the PL intensity without change of its spectral shape (Figure 1b and Figure S7, Supporting Information) whatever the copolymer concentration (Figure S6, Supporting information). Such a decrease of the PL has already been reported in the literature above a critical concentration of polymer in a solvent or when varying the quality of the solvent (by using a mixture of a good and a bad solvent), ${ }^{23,24}$ and shown to be originated by the formation of weakly emissive aggregates. For our solutions of SWNTs/PHTcoAHT in THF, we conclude that the PL quenching without change of the profile when the amount of SWNTs increases can be explained as mainly due to the decrease of the amount of free polymer. This decrease is concomitant with the formation of aggregates growing at the surface of the SWNTs, the growth of such aggregates being controlled by the interaction between the copolymer backbones and SWNTs. ${ }^{25,26}$ This explanation is consistent with the interpretation of the optical absorption spectra measured on the same solutions.

However, opposite to what is reported in the literature, ${ }^{23,24}$ the PL signature of PHTcoAHT aggregates is not observed in our SWNTs/PHTcoAHT suspensions. Associated with the independence of the PL lineshape on the concentration of aggregated copolymer, this could be interpreted as a weakening or quenching of the aggregates emission originated by their interaction with SWNTs.

Figure 2 compares the UV-vis spectra of a suspension of SWNTs dispersed in water with SDS and of a suspension of non-covalent nanohybrids isolated by precipitation in toluene. This process allows one to eliminate most of the free copolymer and residual bundles of SWNTs from the sample (the solvent extraction method is described in Supporting Information). ${ }^{25}$ However, it does not modify sensibly the stability of the suspension. The spectrum of the isolated non-covalent nanohybrids clearly shows the superposition of the 
absorption spectra of PHTcoAHT aggregates, characterized by a band around $500-650 \mathrm{~nm}$, and of carbon nanotubes red shifted in the region $1000-1500 \mathrm{~nm}$ compared to the SDS suspension. The red shift of the optical transitions of the non-covalently functionalized SWNTs is characteristic of strong electronic interactions at the SWNT-copolymer interface. $^{26,27}$

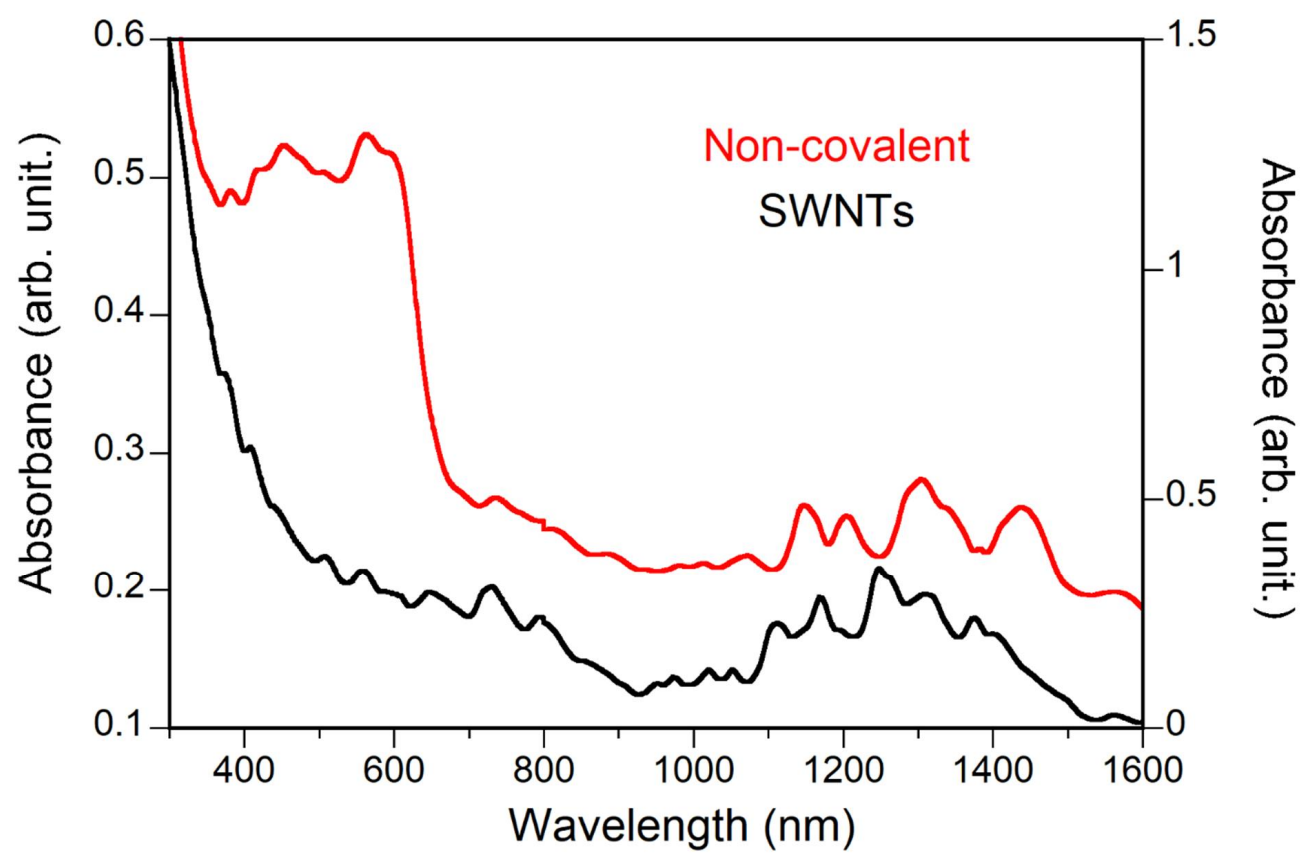

Figure 2. UV-vis spectra of SWNTs dispersed with SDS (black line, left scale) and noncovalent nanohybrids with PHTcoAHT 36000 (red line, right scale) purified by the solvent extraction method.

The results above show the strong $\pi-\pi$ interactions between the thiophene units and the aromatic rings of the nanotubes, overcoming the high planarity of such a conjugated regioregular polymer skeleton. ${ }^{28}$ They are in full agreement with the wrapping of the chains around SWNTs as already reported. ${ }^{29-31}$ Moreover, these results suggest that this wrapping 
could be made of few stacked chains of copolymers and is more efficient for long polymeric chains.

The covalent hybrids were prepared by carrying out Tour's reaction (Scheme 2) on the noncovalent ones. We chose a SWNTs/copolymer concentration ratio (ratio 0.2 and 0.05 for $M_{\mathrm{n}}$ $36000 \mathrm{~g} \mathrm{~mol}^{-1}$ and $5000 \mathrm{~g} \mathrm{~mol}^{-1}$, respectively) well below the critical flocculation ratio determined above to ensure a good dispersion of the tubes. The effect of the temperature of the reaction on the suspension of the non-covalent hybrid has been checked by fluorescence.

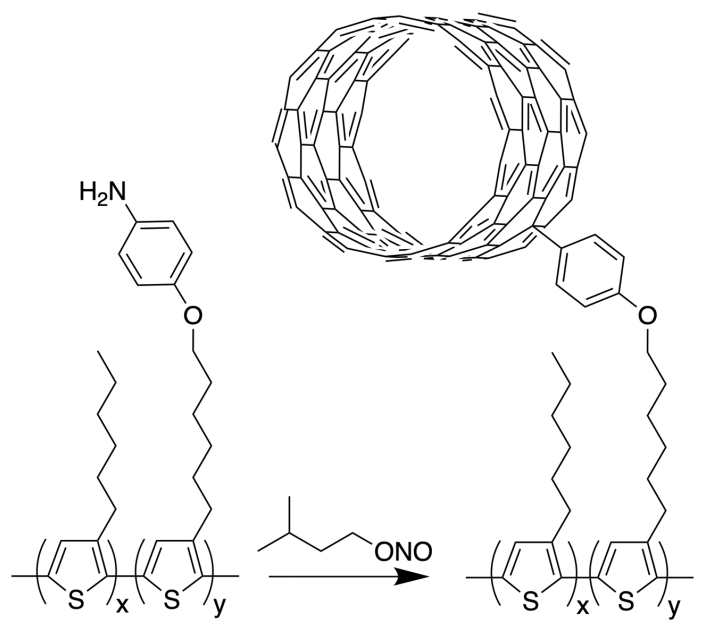

Scheme 2. Structure of the copolymers (PHTcoAHT) synthesized and of the covalent CNT adduct. $\mathrm{x}=86 \%, \mathrm{y}=14 \%$.

Upon heating up to $60^{\circ} \mathrm{C}$, the fluorescence increases rapidly and after 15 minutes reaches a plateau which probably corresponds to an adsorption-desorption equilibrium between the nanohybrids and the surrounding copolymer solution (Figure S8, Supporting Information). This indicates that the copolymer redissolves at least partially, leading to a possible change in the orientation of the aniline group relative to the nanotubes in the suspension, favoring the 
reaction. Important is that Tour's reaction does not affect the copolymer backbone, changes being only observed in the aniline group (see Figure S9 and S10, Supporting Information).

Unlike non-covalent nanohybrids suspensions, the covalent ones are stable up to two months and cannot be isolated by precipitation in toluene. Using the experimental conditions described above for the functionalization of SWNTs, the UV-vis spectrum of both nanohybrids is saturated by the copolymer absorption below $550 \mathrm{~nm}$ (Figure 3 for $M_{\mathrm{n}} 36000 \mathrm{~g}$ $\mathrm{mol}^{-1}$, Figure S11, Supporting Information, for $\left.M_{\mathrm{n}} 5000 \mathrm{~g} \mathrm{~mol}^{-1}\right)$. This prevents the observation of the effect of the functionalization on the SWNTs absorption bands, particularly in the case of a low covalent functionalization rate, as expected. ${ }^{7}$ However, between 1100 and $1500 \mathrm{~nm}$, the SWNTs optical transitions of the non-covalent nanohybrids are red-shifted compared to that of the covalent ones. It indicates that the thiophene units do not stack onto the tubes as easily in the covalent sample as in the non-covalent one. Moreover, the broad band in the range $500-600 \mathrm{~nm}$ characteristic of thiophene aggregates, present in the UV-vis spectrum of the non-covalent nanohybrids, is absent in that of the covalent one. It shows that covalent functionalization increases the disorder in the copolymer chain packing. These UVvis results, together with the drastic difference in the stability of the solutions of both nanohybrids, clearly show that the organization of the copolymer in both systems is different. 


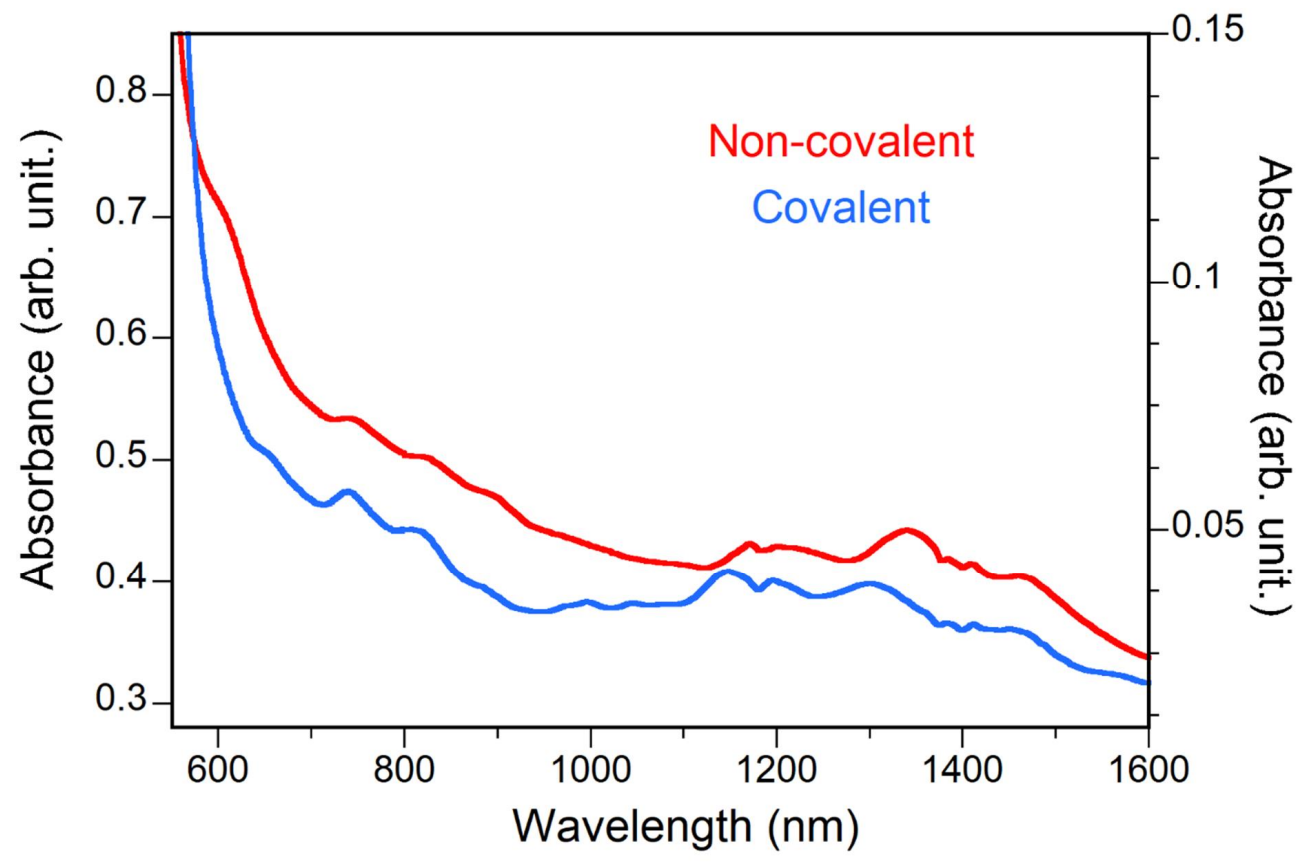

Figure 3. UV-vis spectra of the covalent (blue line right scale), and non-covalent (red line left scale) SWNT/PHTcoAHT 36000.

Examples of Raman spectra excited at $633 \mathrm{~nm}$ of thin films prepared from suspensions of raw, non-covalently (weight ratio of 1.26) and covalently functionalized SWNTs are shown on Figure 4. The Raman modes of SWNTs, i.e. the D band around $1320 \mathrm{~cm}^{-1}$ and the G modes in the $1500-1600 \mathrm{~cm}^{-1}$ range, appear close for the three samples with a $\mathrm{D} / \mathrm{G}$ intensity ratio slightly higher in the covalently functionalized SWNTs. This is consistent with the expected low amount of covalent grafting $\left(10^{-3}\right.$ per $\mathrm{C}$ atom $)$ corresponding to a large distance between defects, of the order of $2-3 \mathrm{~nm}$, and thus negligible changes in $\mathrm{D} / \mathrm{G}$ ratio. ${ }^{8,31}$ On the contrary, the lineshape of the modes of the PHTcoAHT, located in the $1350-1500 \mathrm{~cm}^{-1}$ range, and assigned to the $\mathrm{C}-\mathrm{C}$ intra-ring and $\mathrm{C}=\mathrm{C}$ in-plane symmetric stretching modes respectively (note that these designations do not take into account the complex nature of these collective 
bond stretching modes; ${ }^{32,33}$ however they are sufficiently entrenched in the literature that they have become useful labels irrespective of their accuracy), are different in the non-covalent and covalent samples (Inset Figure 4). It is well established that Raman spectroscopy is deft at probing subtle structural differences at the local order in the polymer stacking, ${ }^{32-35}$ consequently these spectral changes indicate clearly that the organization of the copolymer is not the same in both samples.

Concerning non-covalent nanohybrids, the lineshape of the modes around $1380 \mathrm{~cm}^{-1}$ and $1450 \mathrm{~cm}^{-1}$ is close from the ones obtained on pure polymer thin films as well as those typically reported for "annealed" films in the literature (see Figure 2 of Ref. 35 for example).

On the contrary, the covalent samples appear different and unusual on two different aspects: 1) the appearance of a mode at $1425 \mathrm{~cm}^{-1}$ in the $\mathrm{C}=\mathrm{C}$ vibrations range and 2) an upshift and broadening (or splitting with the appearance of a high frequency component) of the C-C band around $1380 \mathrm{~cm}^{-1}$. Some similarities can be found with the spectra of regiorandom P3HT (RRa-P3HT). ${ }^{34}$ In particular the Raman spectra excited at $633 \mathrm{~nm}$ in Ref. 34, the mode around $1380 \mathrm{~cm}^{-1}$ displays a double peak structure in RRa-P3HT against a single narrow peak in RRP3HT. This behavior observed for RRa-P3HT is however accompanied by an upshift and a broadening of the $\mathrm{C}=\mathrm{C}$ band which is dispersive as a function of laser wavelength which is in disagreement with our observations on the covalent SWNT/PHTcoAHT samples. Overall, the position and intensity of the C-C mode can be modulated by disorder but also by chemical substitution in $\mathrm{C}_{3} .{ }^{33}$ However, the latter can be rejected as after Tour's reaction the copolymer backbone is not modified (Figure S9, Supporting Information) and its Raman spectrum unchanged (Figure S10, Supporting Information). Moreover, based on the calculations, ${ }^{35}$ a splitting of the $\mathrm{C}=\mathrm{C}$ mode, with calculated frequency of each component close with our experimental data, is only expected in the so-called torsional configuration. This 
configuration is plausible as a consequence of the covalent link to the SWNTs, the appended aniline acting as a spacer between SWNTs and the PHTcoAHT skeleton.

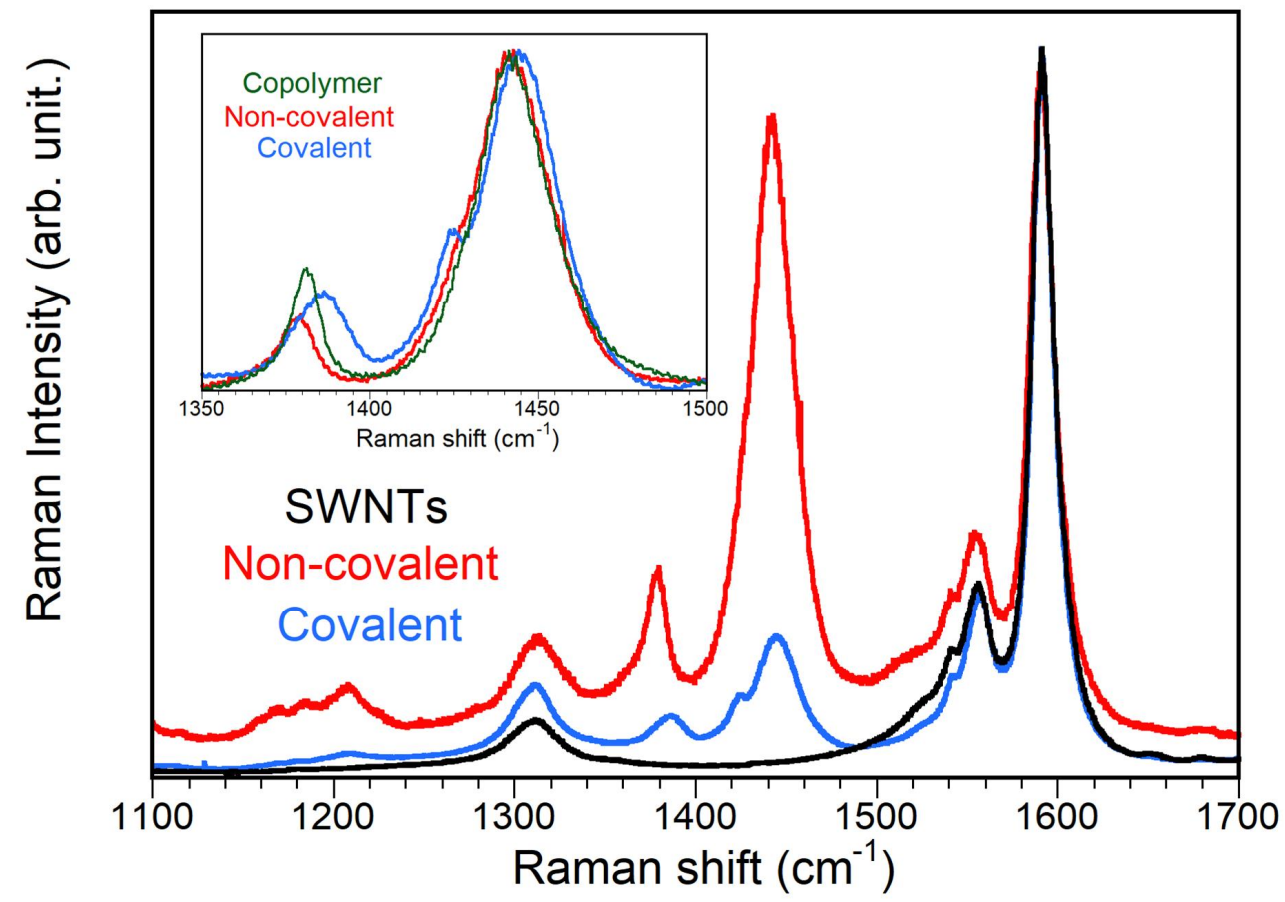

Figure 4. High frequency range of Raman spectra (excitation wavelength $633 \mathrm{~nm}$ ) of thin films of raw SWNTs (black), PHTcoAHT 36000 (green), non-covalent (red) and covalent (blue) SWNT/PHTcoAHT 36000 normalized at $1590 \mathrm{~cm}^{-1}$. Inset: zoom of the thiophene C-C and $\mathrm{C}=\mathrm{C}$ stretching modes in SWNT/PHTcoAHT 36000 non-covalent (red) and covalent (blue) nanohybrids; all the spectra are normalized at $1450 \mathrm{~cm}^{-1}$.

\section{CONCLUSION}

In summary, we have synthesized a copolymer derived from regioregular P3HT in which about $15 \%$ of the monomers bear an aniline group at the end of the hexyl side chain. Like P3HT, this copolymer is able to disperse SWNTs in THF by forming non-covalent 
nanohybrids in the form of one or few layers of chains wrapping around the nanotubes. Starting from these non-covalent systems, a covalent reaction with SWNTs is performed. Despite the small amount of material used in the present study preventing XPS and TGA analysis, the stability of the covalent nanohybrids suspensions and the comparison between both covalent and non-covalent nanohybrids characterizations show that the copolymer organizes differently at the interface with the nanotubes in each case. Due to the covalent grafting by PHTcoAHT side chains, the copolymer adopts a torsional configuration preventing $\pi$ interactions between SWNTs and thiophene units. These results are in full agreement with the effectiveness of the reaction.

\section{EXPERIMENTAL}

\section{General methods}

All the reactions were carried out under argon atmosphere with dry freshly distilled solvents under anhydrous conditions unless otherwise noted. Tetrahydrofuran (THF) was distilled from $\mathrm{Na} /$ Benzophenone. All other chemicals were purchased from commercial suppliers (Aldrich and ACROS) and used without further purification. Chromatographic separations were carried out with silica gel (Geduran 40-63 $\mu \mathrm{m})$.

NMR spectra were recorded on a Bruker WH- $400 \mathrm{MHz}$ spectrometer in $\mathrm{CDCl}_{3}$ and were reported in $\delta$ ppm relative to $\mathrm{Me}_{4} \mathrm{Si}$. The FTIR spectra were recorded on a Bruker Vertex 70 spectrometer equipped with ATR diamond reflection unit (MVPStar).

Size exclusion chromatography: The dry samples $(5 \mathrm{mg})$ were dissolved in THF (5 mL) and a few drops toluene as the flow marker were added and the solution filtered (PTFE, $0.45 \mu \mathrm{m}$ ). $100 \mu \mathrm{L}$ of the solution was injected on a Shimadzu HPLC equipped with a diode array UV detector (SPD-M20A), an Optilab T-rEX refractometer from Wyatt Technology, and a TREOS light scattering detector from Wyatt Technology). The solution was analyzed with a 4 
PL gel mixed C column, thermostated at $35^{\circ} \mathrm{C}$, and calibrated with 15 linear PS standards from Polymer Lab. Preparative SEC was performed on a LaboACE LC-5060 from Japanese Analytical Industries, on a JAIGEL-2HR and JAIGEL-2.5HR columns.

UV - Vis - NIR spectra were recorded with a Varian Cary 5000 or a Perkin Elmer Lambda 25 spectrometer.

Fluorescence spectra were measured with a Horiba-Jobin-Yvon E348 Fluorimeter. A triangular cell was used allowing the analysis of the same solutions as those characterized by UV-vis by getting rid of possible internal filter effects. A rectangular cell $(10 \mathrm{~mm} \times 10 \mathrm{~mm})$ has been used to characterize low concentrated solutions (Figure S6b, Supporting Information).

Raman spectra were recorded using an Acton SP2500 spectrometer fitted with a Pylon CCD detector and a 1800 grooves $/ \mathrm{mm}$ grating. The samples were excited with a $633 \mathrm{~nm}(1.96 \mathrm{eV})$ laser (HeNe, Newport) through 50x objective (Numerical Aperture 0.5) and $0.1 \mathrm{~mW}$ impinging on the sample.

\section{Synthesis}

The synthesis of the two monomers used is detailed in the supporting information (SI section I-A and I-B)

Poly(3-hexylthiophene-co-3-(6-bromohexyl)thiophene) (A): in a $200 \mathrm{~mL}$ reactor equipped with a UV-Vis probe (optical path $151 \mu \mathrm{m}$ ), a solution of dry $\mathrm{LiCl}(464 \mathrm{mg}, 10.9$ mmol) in THF $(120 \mathrm{~mL})$ was stirred at $0{ }^{\circ} \mathrm{C}$. $i$-PrMgCl $(2 \mathrm{M}$ in THF) was added slowly until the absorption of the organomagnesium between 250 and $270 \mathrm{~nm}$ was persistent. 2-bromo-3hexyl-5-iodothiophene $\mathbf{1}$ (751 $\mathrm{mg}, 2.0 \mathrm{mmol})$ and 2-bromo-3-(6-bromohexyl)-5iodothiophene 2 (159 mg, $336 \mu \mathrm{mol})$ were added. $i-\operatorname{PrMgCl}(2 \mathrm{M}$ in THF) was added slowly until no more than $90 \%$ of the monomer is metallated. Aliquots of the medium were sampled, 
quenched with $\mathrm{CD}_{3} \mathrm{OD}$ and the amount of metallated monomers measured (singlet at 6.90 ppm, Figure S1, Supporting Information). The mixture was heated to $20{ }^{\circ} \mathrm{C}$ and $\mathrm{Ni}(\mathrm{dppp}) \mathrm{Cl}_{2}$ (68 mg, $127 \mu \mathrm{mol}, 0.04$ equiv) was added. Reaction was followed by absorption at $440 \mathrm{~nm}$. The reaction was quenched with two drops of aqueous $\mathrm{HCl}(2 \mathrm{M})$. The solution was partially evaporated and the polymer was precipitated in methanol (10 $\mathrm{x}$ the volume of the solution). The polymer was separated from supernatant by centrifugation $(9500 \mathrm{rpm}, 1 \mathrm{~h})$ and dried under vacuum for $24 \mathrm{~h}$ to yield pure A (543 mg, 97\%). The copolymer was dissolved in $\mathrm{CHCl}_{3}$ and further purified by preparative GPC.

${ }^{1} \mathrm{H}$ NMR (400 MHz, $\mathrm{CDCl}_{3}$ ): $\delta(\mathrm{ppm}) 6.99$ (s, thiophene $\left.\mathrm{C} 4-\mathrm{H}\right), 3.43(\mathrm{t}, J=6.8 \mathrm{~Hz}$, $\mathrm{CH}_{2} \mathrm{Br}$ ), 2.81 (m, thiophene- $\left.\mathrm{CH}_{2}\right), 1.89\left(\mathrm{p}, J=6.9 \mathrm{~Hz}, \mathrm{CH}_{2} \mathrm{CH}_{2} \mathrm{Br}\right), 1.71$ (m, hexyl C2- $\mathrm{H}_{2}$ ), 1.57-1.25 (m, 6H, hexyl C3- $\mathrm{H}_{2}, \mathrm{CH}_{2} \mathrm{CH}_{3}$ and hexyl C4- $\left.\mathrm{H}_{2}\right), 0.92\left(\mathrm{~m}, 3 \mathrm{H}, \mathrm{CH}_{3}\right)$;

${ }^{13} \mathrm{C}$ NMR (100 MHz, $\mathrm{CDCl}_{3}$ ) $\delta$ (ppm): 140.1 (thiophene C3), 139.7 (bromohexylthiophene C3), 133.9 (thiophene C5), 130.7 (thiophene $\mathrm{C} 2$ ), 128.8 (thiophene $\mathrm{C} 4), 34.0\left(\mathrm{CH}_{2} \mathrm{Br}\right), 32.9$ (bromohexyl C5), 31.8 (hexyl C4), 30.7 (hexyl C2), 30.5 (bromohexyl C2), 29.6 (hexyl C3), 29.4 (hexyl and bromohexyl C1), 28.8 (bromohexyl), 28.2 (bromohexyl), 22.8 (hexyl C5), $14.3\left(\mathrm{CH}_{3}\right)$;

FTIR (ATR diamond) $v\left(\mathrm{~cm}^{-1}\right): 3055$ (aromatic $\left.v \mathrm{CH}\right), 2953\left(v_{\text {as }} \mathrm{CH}_{3}\right), 2920\left(\mathrm{vas}_{\mathrm{as}} \mathrm{CH}_{2}\right), 2852$ $\left(v_{\mathrm{s}} \mathrm{CH}_{2}\right), 1562,1509$ and 1453 (aromatic $\left.v \mathrm{CC}\right), 1376\left(\delta \mathrm{CH}_{3}\right), 1261,818,723$;

Poly(3-hexylthiophene-co-3-(6-(4-(diphenylimino)phenoxy)hexyl)thiophene) (B): in a pressure tube, $\mathrm{K}_{2} \mathrm{CO}_{3}\left(29 \mathrm{mg}, 210 \mu\right.$ mol, 1.22 equiv) was suspended in a solution of $\mathrm{Bu}_{4} \mathrm{NBr}$ (35 mg, $108 \mu \mathrm{mol}, 0.63$ equiv) and 4-[(diphenylmethylene)amino]phenol (48 mg, $172 \mu \mathrm{mol}$, 1.00 equiv) in DMF (2 mL). A solution of copolymer A (204 mg, $1.15 \mathrm{mmol}, 172 \mu \mathrm{mol}$ of bromohexyl) in THF $(30 \mathrm{~mL})$ was added and the sealed tube was heated to $95{ }^{\circ} \mathrm{C}$ for 4 days. THF was removed in vacuum and the crude was precipitated in ten times its volume of 
$\mathrm{MeOH}$. The polymer was recovered by centrifugation (9500 rpm) and dried $24 \mathrm{~h}$ under vacuum (211 mg, 89\% yield).

${ }^{1} \mathrm{H}$ NMR (400 MHz, $\left.\mathrm{CDCl}_{3}\right): \delta(\mathrm{ppm}) 7.70(\mathrm{~d}, J=7.2 \mathrm{~Hz}$, imine phenyl), 7.47-7.33 (m, $0.44 \mathrm{H}$, imine phenyl), 7.25 (m, imine phenyl), 7.10 (m, $0.28 \mathrm{H}$, imine phenyl), 6.99 (s, $1 \mathrm{H}$, thiophene C4-H), $6.65(\mathrm{~m}, 0.57 \mathrm{H}, J=8.4 \mathrm{~Hz}$, aminophenol H), 3.87 (t, $0.28 \mathrm{H}, J=6.3 \mathrm{~Hz}$, $\left.\mathrm{CH}_{2} \mathrm{O}\right), 2.80\left(\mathrm{~m}, 2 \mathrm{H}\right.$, thiophene- $\left.\mathrm{CH}_{2}\right), 1.71\left(\mathrm{~m}, 2 \mathrm{H}\right.$, thiophene- $\left.\mathrm{CH}_{2} \mathrm{CH}_{2}\right), 1.49-1.40(\mathrm{~m}, 2 \mathrm{H}$, hexyl C), $1.35\left(\mathrm{~m}, 4 \mathrm{H}, \mathrm{CH}_{2} \mathrm{CH}_{3}\right.$ and thiophene- $\left.\left(\mathrm{CH}_{2}\right)_{3} \mathrm{CH}_{2}\right), 0.92\left(\mathrm{~m}, 3 \mathrm{H}, \mathrm{CH}_{3}\right)$.

${ }^{13} \mathrm{C} \mathrm{NMR}\left(100 \mathrm{MHz}, \mathrm{CDCl}_{3}\right) \delta(\mathrm{ppm}): 175.1(\mathrm{C}=\mathrm{N}), 155.6$ (Aryl C-O), 151.7, 144.4 (Aryl $\mathrm{C}-\mathrm{N}), 140.3\left(\mathrm{Ph}_{2} \mathrm{C}=\mathrm{N}\right.$ phenyl $\left.\mathrm{C} 1\right), 140.1$ (thiophene $\left.\mathrm{C} 3\right), 136.8\left(\mathrm{Ph}_{2} \mathrm{CN}\right.$ phenyl $\left.\mathrm{C} 4\right), 135.9$ (phenyl , 133.9 (thiophene C5 HTHT). 130.6 (thiophene C2), 129.7, 129.3, 128.8 (thiophene C4), 128.6, 128.4 (C2 thiophene), 128.3, 128.1, 125.7, 122.7, 114.5, $34.4\left(\mathbf{C H}_{2}\right.$-thiophene protected amine). $31.9\left(\mathrm{CH}_{2}\right.$-thiophene hexyl). $30.7\left(\mathrm{CH}_{2} \mathrm{CH}_{2}\right.$-thiophene hexyl), $30.5\left(\mathrm{CH}_{2}\right.$ $\mathrm{CH}_{2}$-O), $29.6\left(\mathrm{CH}_{2} \mathrm{CH}_{2} \mathrm{CH}_{2}\right.$-thiophene hexyl), 29.5, $29.4\left(\mathrm{CH}_{2} \mathrm{CH}_{2} \mathrm{CH}_{3}\right), 26.1\left(\mathrm{CH}_{2} \mathrm{CH}_{2} \mathrm{CH}_{2}-\right.$ O), $22.8\left(\mathrm{CH}_{2} \mathrm{CH}_{3}\right), 21.3,14.3\left(\mathrm{CH}_{3}\right)$;

FTIR (ATR diamond) $v\left(\mathrm{~cm}^{-1}\right): 3054$ (aromatic $\left.v \mathrm{CH}\right), 2953\left(v_{\mathrm{as}} \mathrm{CH}_{3}\right), 2922\left(v_{\mathrm{as}} \mathrm{CH}_{2}\right), 2853$ $\left(v_{\mathrm{s}} \mathrm{CH}_{2}\right), 1608$ (imine $\left.v \mathrm{CN}\right), 1564,1501$ and 1453 (thiophene $\left.v \mathrm{CC}\right), 1446,1376\left(\delta \mathrm{CH}_{3}\right), 1315$ (aryl C-N stretching), 1238 (vCO ether), 1166 (vC-O ether), 1104 and 958, 819 (oop thiophene $\mathrm{CH}$ ), 783 (imine phenyl $\mathrm{CH}$ bend), 724 (methyl rock), 693 (imine phenyl $\mathrm{CH}$ bend).

\section{Poly(3-hexylthiophene-co-3-((4-aminophenoxy)hexyl)thiophene) $\quad$ (PHTcoAHT): a} solution of copolymer B $(58 \mathrm{mg}, 280 \mu \mathrm{mol}, 40 \mu \mathrm{mol}$ of imine $)$ and hydroxylamine $(0.1 \mathrm{~mL}$, 33 mmol, 35 equiv) in THF ( $2 \mathrm{~mL})$ was heated to $50{ }^{\circ} \mathrm{C}$ under $\mathrm{Ar}$ for $20 \mathrm{~h}$. The resulting polymer was precipitated in $\mathrm{MeOH}$, separated by centrifugation (9500 rpm, $1 \mathrm{~h}$ ) and dried 
under vacuum for $24 \mathrm{~h}$. A shiny violet solid was obtained (50 mg, $98 \%$ yield) (SI section IE).

${ }^{1} \mathrm{H}$ NMR (400 MHz, $\left.\mathrm{CDCl}_{3}\right) \delta(\mathrm{ppm}) 6.99$ (s, 1H, CH thiophene HT-HT coupling), 6.96, 6.73(d, 2H, $J=8.2 \mathrm{~Hz}$, phenyl C2-H and C6-H), $6.62(\mathrm{~d}, 2 \mathrm{H}, J=8.2 \mathrm{~Hz}, \mathrm{CH}$ phenyl C3-H and $\mathrm{C} 5-\mathrm{H}), 5.02(\mathrm{~s}, \mathrm{NH} 2), 3.89\left(\mathrm{t}, 2 \mathrm{H}, J=6.4 \mathrm{~Hz}, \mathrm{CH}_{2} \mathrm{O}\right), 2.81\left(\mathrm{~m}, 2 \mathrm{H}, \mathrm{CH}_{2}\right.$-thiophene HT coupling), 1.71 (m, 2H, $\mathrm{CH}_{2}-\mathrm{CH}_{2}$-thiophene), 1,44 (m, 2H, $\mathrm{CH}_{2}-\mathrm{CH}_{2}-\mathrm{CH}_{2}$ thiophene), 1.35 (m, 4H, $\mathrm{CH}_{2} \mathrm{CH}_{3}$ and thiophene- $\left.\left(\mathrm{CH}_{2}\right)_{3} \mathrm{CH}_{2}\right), 0.93\left(\mathrm{~m}, 3 \mathrm{H}, \mathrm{CH}_{3}\right)$;

${ }^{13} \mathrm{C} \mathrm{NMR}$ (400 MHz, $\left.\mathrm{CDCl}_{3}\right) \delta$ (ppm): 140.1 (C3 thiophene HTHT). 133.9 (C5 thiophene HTHT). 130.7 (C2 thiophene HTHT), 128.8 (C4 thiophene HTHT). 116.6, 115.8, $31.9\left(\mathbf{C H}_{3}\right)$. 30.7 $\left(\mathrm{CH}_{2} \mathrm{CH}_{2}\right.$-thiophene hexyl), 30.5, $29.6 \quad\left(\mathrm{CH}_{2} \mathrm{CH}_{2} \mathrm{CH}_{2}\right.$-thiophene hexyl), 29.4 $\left(\mathrm{CH}_{2} \mathrm{CH}_{2} \mathrm{CH}_{3}\right), 22.8\left(\mathrm{CH}_{2} \mathrm{CH}_{3}\right), 14.3\left(\mathrm{CH}_{3}\right)$;

FTIR (ATR diamond) $v\left(\mathrm{~cm}^{-1}\right): 3361$ (large, NH stretching), 3053 (CH aromatic stretching), 2953, 2922 and 2853 (aliphatic $\mathrm{CH}$ stretching), 1608 (NH bend), 1562 (NH bend), 1510 and 1454 (asymmetric and symmetric ring stretching), 1377 (methyl def.), 1236 (C-O alkyl aryl ether), 819 (aromatic $\mathrm{CH}$ out of plan), 724 (methyl rock).

\section{Elaboration of the nanohybrids.}

HiPCO SWNTs (mean diameter $1.0+/-0.2 \mathrm{~nm}$ ) have been purchased from NanoIntegris. They were dried at $250{ }^{\circ} \mathrm{C}$ under vacuum prior to use.

Dispersion of SWNTs in SDS solution. $10.5 \mathrm{mg}$ of sodium dodecyl sulfate (SDS) were dissolved in $4 \mathrm{~mL}$ of $\mathrm{D}_{2} \mathrm{O} .1 .98 \mathrm{mg}$ of SWNTs were added to this solution and the mixture was sonicated for $5 \mathrm{~min}$ (tip sonication, 20\% of $500 \mathrm{~W}$, Fischer Scientific Model FB-505) then centrifuged ( $25000 \mathrm{~g}$ for $80 \mathrm{~min}$ ). The supernatant was collected and characterized.

SWNTs mother suspension. $0.7 \mathrm{mg}$ of SWNTs were dispersed in THF by sonication (5 minutes). Sonication was repeated for $30 \mathrm{~s}$ before every use. 
Non-covalent nanohybrids were prepared by adding a given volume of the SWNTs mother solution to a solution of copolymer of known concentration. The mixture was then sonicated for 5 minutes (tip sonication, 20\% of 500W, Fischer Scientific Model FB-505) to get the non-covalent hybrids.

Covalent nanohybrids were prepared by Tour's reaction on suspensions of SWNTs/PHTcoAHT in THF (weight ratio of 0.2 and 0.05 for PHTcoAHT 36000 and 5000 respectively to ensure a good dispersion of SWNTs). 10 equiv. of isoamyl nitrite with respect to the amine groups were added to the suspensions and the resulting mixtures were heated at $65{ }^{\circ} \mathrm{C}$ for $12 \mathrm{~h}$ in a sealed Schlenk's vial. The product of the reaction was centrifuged during 5 minutes at $25000 \mathrm{~g}$ and the supernatant was recovered and characterized.

Sonication has no effect on the UV-vis and fluorescence characteristics of a solution of pure copolymer.

Thin films for Raman were prepared by spin coating from a THF solution onto a glass plate then rinsed with THF.

\section{SUPPORTING INFORMATION}

The Supporting Information is available free of charge on the ACS Publications website at DOI:

Details on monomer synthesis, copolymer synthesis and characterization, and copolymer modification and characterization; optical absorbance spectra of nanohybrids obtained with PHTcoAHT 5000; solvent extraction method; and temperature effect on the non-covalent nanohybrids.

\section{AKNOWLEDGEMENTS}


C. Foussat and the facility of polymer characterization are acknowledged for the SEC measurements and for the use of the UV and FTIR spectrometer. J.M. Catala is acknowledged for helpful discussions. M. P., J.-L. S., P. J. M. and P. P. acknowledge financial support from the ANR GAMBIT project, Grant No. ANR-13-BS10-0014 of the French Agence Nationale de la Recherche.

\section{REFERENCES}

(1) Charoughchi, S.; Agbolaghi, S.; Aghapour, S.; Sarvari, R.; Abbasi, F. Polymer Wrapping versus Well-Oriented Crystal Growth of Polythiophenes onto Multi-Wall Carbon Nanotubes via Surface Chemical Modification and Regioregularity Deliberation. New J. Chem. 2018, 42, 14469-14480.

(2) Kuila, B. K.; Park, K.; Dai, L. Soluble P3HT-Grafted Carbon Nanotubes: Synthesis and Photovoltaic Application. Macromolecules 2010, 43, 6699-6705.

(3) Hamdast, A.; Agbolaghi, S.; Zeighami, M.; Beygi-Khosrowshahi, Y.; Sarvari, R. Butterfly Nanostructures via Regioregularly Grafted Multi-Walled Carbon Nanotubes and Poly(3-Hexylthiophene) to Improve Photovoltaic Characteristics. Polym. Int. 2019, $68,335-343$.

(4) Yang, Z.; Yu, J.; Fu, K.; Tang, F. Preparation and Characterization of Poly (3Hexylthiophene) / Carbon Nanotubes Hybrid Material via in-Situ Click Chemistry. Mater. Chem. Phys. 2019, 223, 797-804.

(5) Li, H.; Cheng, F.; Duft, A. M.; Adronov, A. Functionalization of Single-Walled Carbon Nanotubes with Well-Defined Polystyrene by “Click” Coupling. J. Am. Chem. Soc. 2005, 127, 14518-14524. 
(6) Castelaín, M.; Martínez, G.; Merino, P.; Martín $\square$ Gago, J. Á.; Segura, J. L.; Ellis, G.; Salavagione, H. J. Graphene Functionalisation with a Conjugated Poly(Fluorene) by Click Coupling: Striking Electronic Properties in Solution. Chem. Eur. J. 2012, 18, $4965-4973$.

(7) Strano, M. S.; Dyke, C. A.; Usrey, M. L.; Barone, P. W.; Allen, M. J.; Shan, H.; Kittrell, C.; Hauge, R. H.; Tour, J. M.; Smalley, R. E. Electronic Structure Control of Single-Walled Carbon Nanotube Functionalization. Science 2003, 301, 1519-1522.

(8) Piao, Y.; Meany, B.; Powell, L. R.; Valley, N.; Kwon, H.; Schatz, G. C.; Wang, Y. Brightening of Carbon Nanotube Photoluminescence through the Incorporation of Sp3 Defects. Nat. Chem. 2013, 5, 840-845.

(9) Brozena, A. H.; Kim, M.; Powell, L. R.; Wang, Y. Controlling the Optical Properties of Carbon Nanotubes with Organic Colour-Centre Quantum Defects. Nat. Rev. Chem. 2019, 3, 375-392.

(10) Bahr, J. L.; Tour, J. M. Highly Functionalized Carbon Nanotubes Using in Situ Generated Diazonium Compounds. Chem. Mater. 2001, 13, 3823-3824.

(11) Loewe, R. S.; Khersonsky, S. M.; McCullough, R. D. A Simple Method to Prepare Head-to-Tail Coupled, Regioregular Poly(3-Alkylthiophenes) Using Grignard Metathesis. Adv. Mater. 1999, 11, 250-253.

(12) Yokoyama, A.; Miyakoshi, R.; Yokozawa, T. Chain-Growth Polymerization for Poly(3-Hexylthiophene) with a Defined Molecular Weight and a Low Polydispersity. Macromolecules 2004, 37, 1169-1171.

(13) Tahar-Djebbar, I.; Nekelson, F.; Heinrich, B.; Donnio, B.; Guillon, D.; Kreher, D.; 
Mathevet, F.; Attias, A.-J. Lamello-Columnar Mesophase Formation in a Side-Chain Liquid Crystal $\pi$-Conjugated Polymer Architecture. Chem. Mater. 2011, 23, 46534656.

(14) Ouhib, F.; Khoukh, A.; Ledeuil, J.-B.; Martinez, H.; Desbrières, J.; Dagron-Lartigau, C. Diblock and Random Donor/Acceptor "Double Cable" Polythiophene Copolymers via the GRIM Method. Macromolecules 2008, 41, 9736-9743.

(15) Vallat, P.; Lamps, J.-P.; Schosseler, F.; Rawiso, M.; Catala, J.-M. Quasi-Controlled Polymerization through a Nickel Catalyst Process of a Functionalized Thiophene Monomer: Kinetic Studies and Application to the Synthesis of Regioregular Poly(Thiophene-3-Acetic Acid). Macromolecules 2007, 40, 2600-2602.

(16) McCullough, R. D.; Lowe, R. D. Enhanced Electrical Conductivity in Regioselectively Synthesized Poly(3-Alkylthiophenes). J. Chem. Soc. Chem. Commun. 1992, 70 - 72.

(17) Sato, M.; Morii, H. Nuclear Magnetic Resonance Studies on Electrochemically Prepared Poly(3-Dodecylthiophene). Macromolecules 1991, 24, 1196-1200.

(18) Loegers, M.; Overman, L. E.; Welmaker, G. S. Mannich Biscyclizations. Total Synthesis of (-)-Ajmalicine. J. Am. Chem. Soc. 1995, 117, 9139-9150.

(19) Fasth, K.; Antoni, G.; Langström, B. Asymmetric Synthesis of L-[3- $\left.{ }^{11} \mathrm{C}\right]$ Alanine and L-[3- $\left.{ }^{11} \mathrm{C}\right]$ Phenylalanine by a Phase-Transfer Alkylation Reaction. J. Chem. Soc., Perkin Trans. 1 1988, 3081-3084.

(20) Jakubka, F.; Schießl, S. P.; Martin, S.; Englert, J. M.; Hauke, F.; Hirsch, A.; Zaumseil, J. Effect of Polymer Molecular Weight and Solution Parameters on Selective Dispersion of Single-Walled Carbon Nanotubes. ACS Macro Lett. 2012, 1, 815-819. 
(21) Rice, N. A.; Subrahmanyam, A. V.; Laengert, S. E.; Adronov, A. The Effect of Molecular Weight on the Separation of Semiconducting Single-Walled Carbon Nanotubes Using Poly(2,7-Carbazole)S. J. Polym. Sci. Part A Polym. Chem. 2015, 53, $2510-2516$.

(22) Spano, F. C.; Silva, C. H- and J-Aggregate Behavior in Polymeric Semiconductors. Annu. Rev. Phys. Chem. 2014, 65, 477-500.

(23) Clark, J.; Silva, C.; Friend, R. H.; Spano, F. C. Role of Intermolecular Coupling in the Photophysics of Disordered Organic Semiconductors: Aggregate Emission in Regioregular Polythiophene. Phys. Rev. Lett. 2007, 98, 206406.

(24) Rumbles, G.; Samuel, I. D. W.; Magnani, L.; Murray, K. A.; DeMello, A. J.; Crystall, B.; Moratti, S. C.; Stone, B. M.; Holmes, A. B.; Friend, R. H. Chromism and Luminescence in Regioregular Poly(3-Dodecylthiophene). Synth. Met. 1996, 76, 4751.

(25) Schuettfort, T.; Snaith, H. J.; Nish, A.; Nicholas, R. J. Synthesis and Spectroscopic Characterization of Solution Processable Highly Ordered Polythiophene-Carbon Nanotube Nanohybrid Structures. Nanotechnology 2010, 21, 025201.

(26) Roquelet, C.; Lauret, J. S.; Alain-Rizzo, V.; Voisin, C.; Fleurier, R.; Delarue, M.; Garrot, D.; Loiseau, A.; Roussignol, P.; Delaire, J. A.; et al. П-Stacking Functionalization of Carbon Nanotubes through Micelle Swelling. ChemPhysChem 2010, 11, 1667-1672.

(27) Schuettfort, T.; Nish, A.; Nicholas, R. J. Observation of a Type II Heterojunction in a Highly Ordered Polymer-Carbon Nanotube Nanohybrid Structure. Nano Lett. 2009, 9, 3871-3876. 
(28) Osaka, I.; McCullough, R. D. Advances in Molecular Design and Synthesis of Regioregular Polythiophenes. Acc. Chem. Res. 2008, 41, 1202-1214.

(29) Fujigaya, T.; Nakashima, N. Non-Covalent Polymer Wrapping of Carbon Nanotubes and the Role of Wrapped Polymers as Functional Dispersants. Sci. Technol. Adv. Mater. 2015, 16, 024802.

(30) Giulianini, M.; Waclawik, E. R.; Bell, J. M.; Scarselli, M.; Castrucci, P.; De Crescenzi, M.; Motta, N. Microscopic and Spectroscopic Investigation of Poly(3-Hexylthiophene) Interaction with Carbon Nanotubes. Polymers. 2011, 3, 1433-1446.

(31) Giulianini, M.; Waclawik, E. R.; Bell, J. M.; Crescenzi, M. De; Castrucci, P.; Scarselli, M.; Diociauti, M.; Casciardi, S.; Motta, N. Evidence of Multiwall Carbon Nanotube Deformation Caused by Poly(3-Hexylthiophene) Adhesion. J. Phys. Chem. C 2011, $115,6324-6330$.

(32) Wood, S.; Hollis, J. R.; Kim, J. S. Raman Spectroscopy as an Advanced Structural Nanoprobe for Conjugated Molecular Semiconductors. J. Phys. D. Appl. Phys. 2017, 50.

(33) Brambilla, L.; Tommasini, M.; Botiz, I.; Rahimi, K.; Agumba, J. O.; Stingelin, N.; Zerbi, G. Regio-Regular Oligo and Poly(3-Hexyl Thiophene): Precise Structural Markers from the Vibrational Spectra of Oligomer Single Crystals. Macromolecules 2014, 47, 6730-6739.

(34) Tsoi, W. C.; James, D. T.; Kim, J. S.; Nicholson, P. G.; Murphy, C. E.; Bradley, D. D. C.; Nelson, J.; Kim, J. S. The Nature of In-Plane Skeleton Raman Modes of P3HT and Their Correlation to the Degree of Molecular Order in P3HT:PCBM Blend Thin Films. J. Am. Chem. Soc. 2011, 133, 9834-9843. 
(35) Sainbileg, B.; Lan, Y. B.; Wang, J. K.; Hayashi, M. Deciphering Anomalous Raman Features of Regioregular Poly(3-Hexylthiophene) in Ordered Aggregation Form. $J$. Phys. Chem. C 2018, 122, 4224-4231.

For Table of Contents only

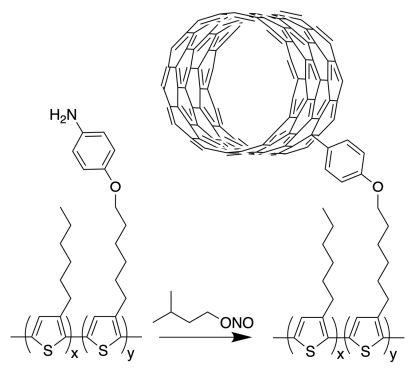

